研究課題別評価

1 .研究課題名 :二元金属集積体の異成分挿入による磁気光学特性の制御

2.研究者氏名 :大場 正昭

3. 研究のねらい:

金属錯体や有機ラジカルなどの分子を基に合成した磁性体は、一般の合金や金属酸化物磁 性体と区別して 分子磁性体」と呼ばれている。無機イオンと有機分子のハイブリッド体である金 属錯体をモジュールとした分子磁性体は、立体構造 ·電子構造の合理的設計、組成や相互作用 の制御が可能である。さらに結晶性の磁性体を有色透明磁性体」と見なすことかでき、いわゆる 磁石の性質の他に、磁化によって偏光応答性か変化する磁気光学効果が期待される。本研究で は、構造秩序を有する有色透明磁性体に反磁性成分を挿入し、磁気秩序状態から磁気的無秩序 状態を作り上げ、マクロの構造秩序を保持したままて磁気中心配列を無秩序化して磁区を分断す ることによりバルクの磁気特性及ひ磁気光学特性の制御を発案した。高機能性磁気光学材料 開発を目指して、反磁性成分插入による組成変化と磁性の相関を検証し、磁気相転移現象の定 性的理解、並びに構成成分の多元化や外場摂動による磁気及び磁気光学特性の制御を試み た。

4 . 研究結果 :

(1) 反磁性成分挿入による三元金属集積体の磁気及ひ磁気光学特性

強磁性を示す二次元 $\mathrm{Fe}(\mathrm{III}) \mathrm{Ni}(\mathrm{II})$ 集積体の Fe(III) のサイトを反磁性の Co(III) に部分的に置 き換えることで、 $\mathrm{Fe}(I I I)_{\mathrm{x}} \mathrm{Co}(\mathrm{III})_{1-\mathrm{x}} \mathrm{Ni}(\mathrm{II})$ 三元金属集積体を合成し、磁区の分断による磁気及び磁気 光学特性の制御を試みた。Co(III) の割合を $x=0 \square$ 1まて変化させ、全ての割合における単結晶 X線構造解析、IR, 磁気測定の結果から、Co(III) が同一の構造を保持したままで二次元構造内 に平均分散されていることを確認した。

磁気特性においては、Co(III) の比率の増加とともに磁区構造が分断された結果、磁気相転移 温度 $\mathrm{T}_{\mathrm{c}}$ の低下及ひ交流磁化のピークの尖鋭化が観測された。バルクの磁気挙動は Co(III) の増 加に伴い、強磁性 - スピングラス - 常磁性と変化した。自発磁化の消滅する臨界点は、 $x=0.76$ と見積もられた。2次元格子系のボンドパーコレーショ ンによる理論的臨界值は $x=0.5$ であるが、この系は 2次元格子内に常磁性の $\mathrm{Ni}(I I)$ が常に存在している ために、臨界値が上がつたものと解釈した。

磁気光学特性においては Co(III) の挿入により、 反磁性成分の増加と磁区の分断による磁化の減少と 吸光係数の大きな Fe- CN の LMCT の減少のため、 ファラデー楕円率は著しく減少した。 $x=1.00$ のファラデ 一楕円率の最大值は、 $x=0.00$ と比べて一万分の一以 下となった。

Co(III) の挿入による磁気及び磁気光学特性の変

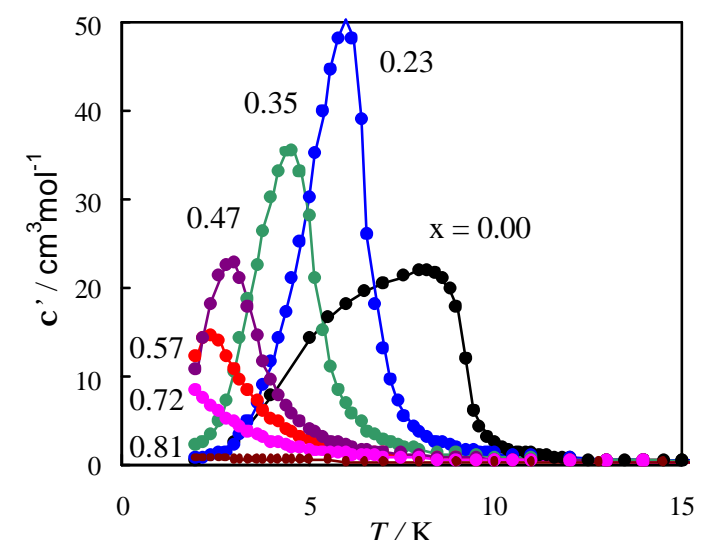

Fig. $1 \mathrm{Fe}(\mathrm{III})_{\times} \mathrm{Co}(\mathrm{III})_{1-\mathrm{x}}^{T}$ 低(II)三元金属集積 体の $\chi^{\prime} v s . T$ プロット 
化は確認できたが、 $\mathrm{T}$ ～が低いため、クライオスタットの最低到達温度 $6.0 \mathrm{~K}$ では磁場依存などの データが取れず、スピングラス的挙動を示す領域での外場応答性なと詳細な検討については課 題が残つた。

(2)脱水／吸湿による磁気及び磁気光学特性変換

二次元グリット型 $\mathrm{Fe}(\mathrm{III}) \mathrm{Ni}(I I)$ 集積体のシー間に存在する格子水の除去により、バルクの磁 性を強磁性からメ名磁性 反強磁性)へと变換した。TGA, XRD, IR より，加熱脱水処理により二次 元グリット構造は保持されたまま、脱水によりシート間距離が縮むことを確認した。この脱水によ る磁気変換に対応して、脱水後はファラデー楕円率の強度が3行以上減少した。

一次元鎖が配位水と水素結合て連結した構造を形成している擬二次元型 Fe(III)Ni(II) 集積体 では、加熱処理により配位水が外れ新たな結 合を形成し二次元グリット構造へと変化すること をTGA, XRD, IR よ確認した。この構造変化に より、バルクの磁性はメ名磁性から強磁性へと 変化した。またファラデー楕円率においては、脱 水後は磁化の増加を反映した強度の増加に加 えて、 $\mathrm{Fe}(\mathrm{III})$ 周りの配位環境の変化を反映した 符合の反転も観測された。脱水サンプルは、容 易に吸湿して初期状態に戻った。分子磁性体 の柔軟な構造を利用して、脱水／吸湿による磁 気及び磁気光学特性の可逆的変換が達成でき た。

(3)圧力による磁気及ひ磁気光学特性変換

二次元グリット型 $\mathrm{Fe}(\mathrm{III}) \mathrm{Ni}$ (II) 集積体を用いて、圧 力によるシー間距離 ヒー間相互作用)の変化を卜 リガーとする磁気特性制御を検討した。クランプ式圧 カセルを用いて静水圧をかけることで、6 kbar 付近か ら磁化曲線に変曲点か現れ、9 kbar ではほぼ完全に メ多磁性的挙動へと変化した。圧力を開放すると構造 を保持したまま元の強磁性体に戻り、可逆的な磁性変 換を達成できた。

メ夕磁性へと変化する臨界圧力は、シー間に挿入 するアニオンにより構造を調整することで制御できた。 三次元 $\operatorname{Cr}(I I I) M n(I I)$ フェリ磁性体を用いた場合は、 $13.6 \mathrm{kbar}$ までの加圧により、 $\mathrm{T}_{\mathrm{C}}$ が $69 \mathrm{~K}$ から $102 \mathrm{~K}$ ま

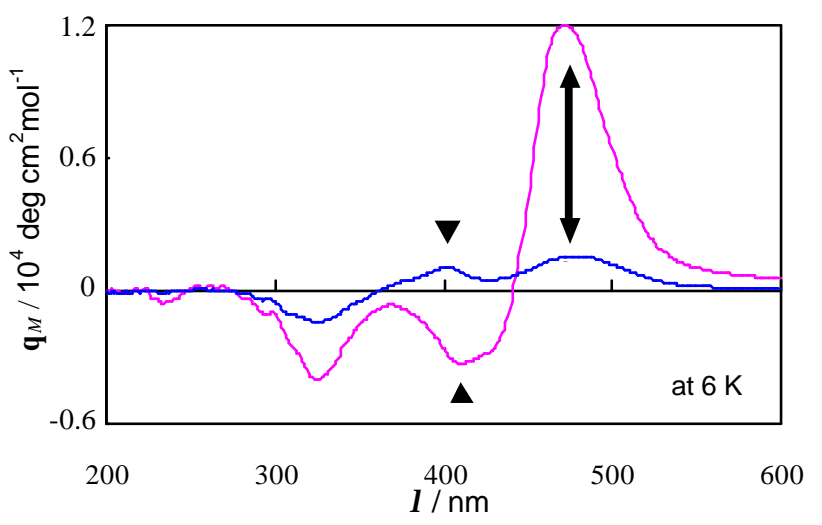

Fig. 2 脱水/吸湿によるファラデースペクト ルの可逆的変換

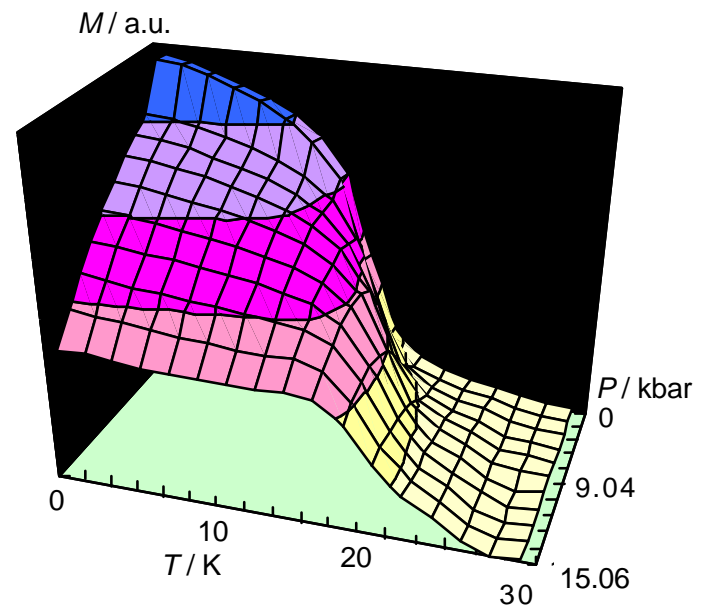

Fig. 3 加圧による磁気特性変換 で上昇した。これは、加圧により架橋金属間距離が縮まり、磁気軌道の重なりが増すことで反強 磁性的相互作用か増したことに起因する。今後はダイアモンドアンビルセルを用いて圧力下で構 造を決定し、構造変化と相互作用との相関を調べる。高圧下での磁気光学特性評価に関しては 装置の構造上の問題があり、今後の課題として残つた。

(4) 新規 $M(I I) L n(I I I) M '$ (III) 三元金属集積型磁性体

これまでの 3d 金属 (M, M') を用いた磁性系に 磁気異方性が大き特徵的な f- $f$ 遷移を示 
す $4 \mathrm{f}$ 金属 (Ln) を挿入して、三元金属集積系への展開を検 討した。前駆体として $\mathrm{M}_{2}(\mathrm{II}) \operatorname{Ln}(\mathrm{III})$ 三核錯体 $(\mathrm{M}=\mathrm{Co}, \mathrm{Ni}, \mathrm{Cu}$, $\mathrm{Zn} ; \mathrm{Ln}(\mathrm{III})=\mathrm{La}, \mathrm{Ce}, \cdots, \mathrm{Yb}, \mathrm{Lu})$ を系統的に合成し、光れを更 に集積させることで、一連の M(II)Ln(III)M' (III) 三元金属集積 体の系統的合成に成功した。前駆体の磁性評価を踏まえて、 集積体の構造決定、磁気及び磁気光学特性評価を行った。 三次元型 $\mathrm{Co}(\mathrm{II}) \operatorname{Ln}(\mathrm{III}) \mathrm{Cr}$ (III) 集積体では、Co(II)Cr(III) で形成 される二次元シー間を Ln(III) が連結しているため、Ln(III) を換えることでシー間相互作用を制御することができ、光 の種類によりメ久磁性、フェ1磁性、強磁性が発現した。現在

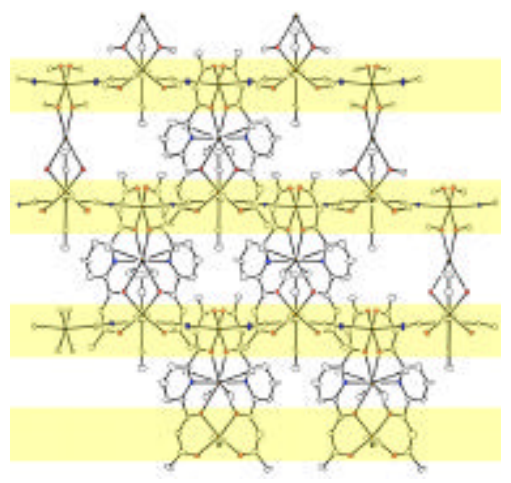

Fig. $4 \mathrm{Co}(\mathrm{II}) \mathrm{Cr}(\mathrm{III})$ の二次元シ 一トと Ln(III) の交互配列

は、 $\operatorname{Ln}(I I I)$ の光学的性質を利用した磁性制御、並びに $M(I I) L n(I I I)$ 間の相互作用に対する圧力効 果を検討している。

(5) キラル磁性体

集積構造内に意図的に光学活性な分子を挿入することで、キラル構造由来の円二色性と磁気 由来の磁気円二色性を併せ持つ化合物の合成を目指した。

二次元型 $\mathrm{Fe}(\mathrm{III}) \mathrm{Ni}$ (II) 集積体に1,2- diaminocyclohxane を挿入して、ラセミ RR- 体、SS- 体を作 り分け構造決定した。全て強磁性を示し、LMCT 由来の吸収帯で大きなファラデー楕円率を示し た。キラル体においては、ゼロ磁場下で弱いながらも CD か観測され、両化合物において、光の 符号は反転した。さらに磁場を印加すると、構造由来の CD か磁気由来の MCD に重なつた非 対称なスペクトルが得られた。温度を下げていく、、磁化の増加によりファラデ一楕円率のみか増 加するため、極低温域においては、CD の寄与は観測できなかった。この他にも 1,2- diaminopropane などを用いたキラル磁性体を合成し、磁気及び磁気光学特性を評価した。

キラルな磁性体では円二色性と磁気円二色性に加えて、弚の交差による磁気不斉二色性 (Magneto- Chiral Dichroism: MChD) の発現が予測されている。しかし、実際に MChD を観測する 場合は、光学測定に耐えうる数 $\mathrm{mm}$ サイズの安定な単結晶を必要としており、今後は結晶サイ ズの調整が課題である。

\section{5.自己評価 :}

本研究では設計性の高い分子磁性体の長所を活かして、樣々な化合物を系統的に合成し、光 の磁気及び磁気光学特性を評価した。合成面では多元スピン集積型分子磁性系への展開、物性 面では外場による磁気及ひ磁気光学特性の制御に成功した。

当初計画による、異成分挿入により磁気及ひ磁気光学特性を変化させることはできたが、測 定温度などの事情て詳細な測定ができず、磁区構造の分断によって生じた磁性相における外場 応答性などの評価には課題が残つた。統計的解釈については、単純なパーコレーションモデルを 適応したレベルでの解析にとどまつた。異成分を拡大解釈して、希土類イオンや光学活性有機分 子を導入した系では新規化合物群を開拓することかでき、とれなりの成果を収められたと思う。特 に 3d-4f-3d 三元金属集積系は、全ての希土類イオンを用いて数十種類の化合物を系統的に合 成 評価することかでき、今後に有用な基礎的データを蓄積できた。

磁気光学特性評価については、新たに装置を立ち上げノウハウを蓄積して測定技術を上げる のに時間を要したが、媒体を有色透明磁性体とすることての大きなファラデー楕円率の発現、構 
造変化を伴磁気変換による、ファラデー楕円率の強度及び符号の変換など、特徵ある結果が得 られた。圧力や湿度を外場とすることで磁気及ひ磁気光学特性の変換と制御も達成できたのは、 機能性材料への展開を期待させる結果であると思う。今後は、残つた課題を解決しつつ、この3年 間で蓄積したデータを踏まえて、光や電場を外部摂動とした磁気及び磁気光学特性変換へと展 開していく

\section{6 .研究総括の見解 :}

構造秩序を持つ有色透明磁性体に反磁性成分を挿入して磁気秩序状態から磁気的無秩序状 態を作り上げ、マクロの構造秩序を保持したままでバルクの磁気特性及び磁気光学特性の制御 を行おうとい極めて挑戦的な研究であつた。測定温度などの事情て詳細な測定が遅れ、また新 たな装置の立ち上げに時間を要したが、当初計画による異成分挿入により磁気及び磁気光学特 性を変化させることができ、大きなファラデー楕円率の発現などで特徵ある結果が得られたことは 高〈評価できる。目標とする高機能性磁気光学材料開発にはまだ残された課題はあるものの、組 成と磁性の相関を検証し、磁気相転移現象を定性的に理解して、構成成分の多元化や外場捸動 によって磁気及ひ磁気光学特性の制御に成功していることから、今後世界的に高し評価を得るよ うになると思われる。

\section{7 .主な論文等 :}

論文

1. A Three- dimensional Ferrimagnet with a High Magnetic Transition Temperature $\left(T_{C}\right)$ of $53 \mathrm{~K}$ Based on a Chiral Molecule, K. Inoue, H. Imai, P. S. Ghalsasi, K. Kikuchi, M. Ohba, H. ?kawa, J . V. Yakhmi, Angew. Chem. Int. Ed, 40, 4242 (2001).

2. Three- Dimensional Bimetallic Ferrimagnets $[\mathrm{Mn}(\mathrm{L})]_{3}\left[\mathrm{Cr}(\mathrm{CN})_{6}\right]_{2} \cdot \mathrm{nH}_{2} \mathrm{O}$ and Relevance to a Prussian Blue Analogue $\mathrm{Mn}_{3}\left[\mathrm{Cr}(\mathrm{CN})_{6}\right]_{2} \cdot 12 \mathrm{H}_{2} \mathrm{O}, \mathrm{N}$. Usuki, M. Yamada, M. Ohba, H. ?kawa, J . Solid State Chem., 159, 328 (2001).

3. Structures and Magnetism of Cyanide- Bridged Bimetallic Compounds: Design and ComplexBased Magnetic Materials, H. ?kawa, M. Ohba, Bull. Chem. Soc. J pn., 75, 1191 (2002).

4. Magneto- optical Properties of Two- dimensional Cyanide- Bridged $\mathrm{M}^{\mathrm{II}} \mathrm{Ni}$ il Bimetallic Assemblies ( $\mathrm{M}=\mathrm{Fe}, \mathrm{Co}$ ), M. Ohba, T. Iwamoto, H. ?kawa, Chem. Lett, 1046 (2002).

5. A Bimetallic Magnetic System Exhibiting Reversible Ferromagnetism/Metamagnetism Modulation, N. Usuki, M. Ohba, H. ?kawa, Bull. Chem. Soc. J pn., 75, 1693 (2002).

6. New 3 D Bimetallic Magnetic Compounds, $[\mathrm{Ni}(\mathrm{dipn})]_{3}\left[\mathrm{Fe}(\mathrm{CN})_{6}\right]_{2} \cdot 7 \mathrm{H}_{2} \mathrm{O}, \mathrm{M}$. Ohba, M. Yamada, N. Usuki, H. ?kawa, Mol. Cryst. Liq. Cryst., 379, 241 (2002).

7. Synthesis and Characterization of a Tetrahedral and Octahedral Cobalt(II) Alternate Chain Complex, H. Kumagai, M. Ohba, K. Inoue, ?kawa, Chem. Lett, 1006 (2002)

8. Structure and Magnetism of a Trinuclear $\mathrm{Cu}^{\prime \prime} \mathrm{Gd}^{\text {III }} \mathrm{Cu}^{\text {"l }}$ Complex Derived from One- pot Reaction with 2,6- di(acetoacetyl)pyridine, T. Shiga, M. Ohba, H. ?kawa, Inorg. Chem. Commun., 6, 15 (2003)

9. Structure and Magnetic Properties of a Chiral Two- dimensional Ferrimagnet with $\mathrm{T}_{\mathrm{C}}$ of $38 \mathrm{~K}, \mathrm{~K}$. Inoue, K. Kikuchi, M. Ohba, H. ?kawa, Angew. Chem. Int. Ed, 42, 4810 (2003)

10. Synthesis, Structure and Magnetic Properties of a Linear $\mathrm{Cu}(\mathrm{II}) \mathrm{Cu}(\mathrm{II}) \mathrm{Gd}(\mathrm{III})$ Complex, M. Ohba, 
N. Ohtsubo, T. Shiga, M. Sakamoto, H. ?kawa, Polyhedron, 22, 1905 (2003).

11. Hydrothermal synthesis, crystal structure and characterization of a new hexanuclear cobalt(II) complex comprised of octahedral and tetrahedral cobalt ions, H. Kumagai, Y. Oka, S. Kawata, M. Ohba, K. Inoue, M. Kurmoo, H. ?kawa, Polyhedron, 22, 1917 (2003)

12. A series of Trinuclear Cu"Ln"'C Cu" Complexes Derived from 2,6- Di(acetoacetyl)pyridine: S ynthesis, Structure and Magnetism, T. Shiga, M. Ohba, H. ?kawa, Inorg. Chem., in press (2003)

13. Heterotrinuclear M- Gd"I- M" complexes: structure and magnetism, T. Shiga, M. Ohba, H. ?kawa, Eur. J. Inorg. Chem., to be submitted (2003)

14. A Novel Three- dimensional Trimetallic Ferrimagnet, $\left[\mathrm{Co}_{2} \mathrm{Sm}(\mathrm{L})_{2}\right]\left[\mathrm{Cr}(\mathrm{CN})_{6}\right] 4 \mathrm{H}_{2} \mathrm{O},\left(\mathrm{H}_{2} \mathrm{~L}=2,6\right.$ - Di (acetoacetyl)pyridine), T. Shiga, M. Ohba, H. ?kawa, Angew. Chem. Int. Ed., to be s ubmitted (2003)

\section{解説記事}

1. 分子磁性体の円二色性スペクトル(MCD), 大場正昭, J asco Report, 45, 33, (2003)

2. シアノはし架け二元金属磁性体, 大場正昭, 大川尚士, 集積型金属錯体の科学, 化学同人, 147 (2003)

招待 依頼講演

1. Magneto- optical Properties of Cyanide- bridged Bimetallic Assemblies, $8^{\text {th }}$ Eurasia Asia Chemical Conference, ハソイ 平成 15年 10月 23日)

2. 私の歩んできた道、特別講演会、福岡県甘木市立秋月小学校 秋月中学校、平成 15年 11 月 17 日)

3. シア 架橋二元金属分子磁性体の可逆的フエロ磁性/メ多磁性変換、日本化学会第 83 春季 年会、早稲田大学 平成 15年 3月 20日)

4. 分子性透明磁性体の合成と磁気および磁気光学特性の研究、日本化学会第 83 春季年会、 早稲田大学 平成15年3月18日)

5. 外場応答型分子磁石の合成と磁気及び磁気光学特性、京都大学 21世紀 COE シンポジウ 厶、京都大学 平成15年 3月1日)

6. 金属錯体を用いた透明磁石の合理的合成と磁気及び磁気光学特性、名古屋大学 21 世紀 $\mathrm{COE}$ シンポジウム、名古屋大学 平成15年1月11日)

7. 透明磁性体の化学的設計と磁気光学特性、2002年日本化学会西日本大会、九州工業大学 平成 14年 11月 2日)

8. 二次元型分子磁石の秩序磁性相制御と磁気光学特性、第 52 回錯体化学討論会特別シンポ ジウム、東京大学 平成14年10月 1日)

9. 二次元磁性体における磁気秩序相の可逆的変換、研究会イン冲縄 2002、琉球大学 平成 14 年 4月 26日)

10. シアン架橋多元金属集積体の磁気相及び磁気光学特性、日本化学会第 81 春季年会、早稲 
田大 平成 14年 3月 28日)

11. 多元金属集積型錯体の構造と磁気特性、メスバウア一研究会、福岡 平成 13年 10月30日)

12. 分子磁性体設計における磁気的相互作用と構造の制御、錯体化学若手の会夏の学校、京都 平成 13年 8月 12日)

13. 3d-3d'- 4f 三元金属集積体の構造と磁気特性、研究会イン゙冲縄 2001、琉球大学 平成 13年 4 月 27日)

14. シアン架橋分子磁性体の磁気相変換と磁気光学特性、Condenced Molecular Materials Seminor、分子研 平成 13年 2月 15日)

15. シアン架橋 3d-4f-3d' 三元金属集積型錯体の構造と磁気特性、分子研研究会 無機金属化 学の展望」、分子研 平成 13年1月 29日)

16. 3 D Bimetallic Ferro- and Ferrimagnets Extended by Cyanide- Bridge、Pacifichem 2000、ハワ 个平成12年12月17日)

17. 三元金属集積体の磁気特性 秩序及ひ無秩序系からのアプローチ、特定領域研究 金属集積 型錯体」シンポジウム、琉球大学 平成 12年11月 11日)

出願特許

1. 圧力応答型磁石および光の製造方法、申請準備中

授賞

1. 日本化学会進歩賞、分子性透明磁性体の合成と磁気およひ磁気光学特性、平成 15年 3月

2. BCSJ 賞 日本化学会欧文誌賞)、A Bimetallic Magnetic System Exhibiting Reversible Ferromagnetism/Metamagnetism Modulation、平成 14年 8月

3. 九州大学総長奨励賞、 $[\mathrm{Mn}(\mathrm{en})]_{3}\left[\mathrm{Cr}(\mathrm{CN})_{6}\right]_{2} \cdot 4 \mathrm{H}_{2} \mathrm{O}:$ A Three- Dimensional Dimetallic Ferrimagnet $(T c=69 \mathrm{~K})$ with a Defective Cubane Unit、平成 13年 3月 